\title{
Can Clean Energy Consumption Promote the Decoupling Between Economic Growth and Environmental Pollution? - Spatial Empirical Analysis Based on China
}

\author{
Hong Shen ${ }^{1}$, Yifan Wang ${ }^{2 *}$, Rumeng Deng ${ }^{2}$ \\ ${ }^{1}$ Business College, Guilin University of Technology, Guilin 532100, China \\ ${ }^{2}$ College of Public Administration, Huazhong University of Science and Technology, Wuhan 430074, China
}

Received: 6 October 2020

Accepted: 20 December 2020

\begin{abstract}
High hopes are placed on the production and use of clean energy during the decoupling between economic growth and environmental pollution. This article uses the decoupling model to study the temporal and spatial coupling characteristics of economic growth and environmental pollution in different regions of China. On this basis, a spatial measurement model is used to quantitatively evaluate the effects of clean energy consumption on the decoupling of economic growth and environmental pollution. The results show that during the study period, the areas where economic growth and environmental pollution generally showed strong decoupling gradually increased, and the areas showing coupling gradually decreased. Moreover, the decoupling state has obvious spatial heterogeneity and spatial aggregation characteristics. Clean energy consumption can significantly promote the decoupling of economic growth and environmental pollution. In addition, the analysis of direct effects shows that clean energy consumption has a significant negative effect on the decoupling of regional economic growth from $\mathrm{SO}_{2}$ emissions and DS (dust and smoke) emissions. But the indirect effect and total effect are not obvious. It further proves that clean energy consumption has no significant effect on promoting the decoupling of surrounding areas and all areas except the local area.
\end{abstract}

Keywords: decoupling, environment pollution, clean energy, spatial econometrics, agglomeration

\section{Introduction}

Economic development and environmental pollution are a pair of strongly coupled partners in the development process of most developing countries.

*e-mail: wangyifanhust@hust.edu.cn
Green Peace Southeast Asia and the Centre for Research on Energy and Clean Air have released a new report about the costs of air pollution from fossil fuels, both human and economic. Burning gas, coal and oil results in three times as many deaths as road traffic accidents worldwide and it is estimated that air pollution has a \$2.9 trillion economic cost, equating to 3.3 percent of the world's GDP. In 2018, the report estimates that it was linked to 4.5 million deaths with PM2.5 pollution 
also responsible for 1.8 billion days of work absence, 4 million new cases of child asthma and 2 million preterm births [1].

With the rapid growth of China's economy, China's demand for energy has increased rapidly. However, China's energy structure is dominated by energy with high pollution emissions, and clean energy accounts for a small proportion. China's energy market is dominated by coal accounting for $62 \%$, far exceeding the average level of $20 \%$ in developed countries [2]. Therefore, the increase in energy demand in China will cause a lot of environmental pollution, especially air pollution. The $\mathrm{SO}_{2}$ and $\mathrm{NOx}$ in the air pollutants can cause acid fog and acid rain, and have a serious negative impact on economic development. Dust and smoke in air pollutants can cause smog and cause serious damage to citizens' health and social welfare. The total annual cost of air pollution in China is estimated to be $\$ 900$ billion each year with costs in the U.S. running to $\$ 600$ billion annually. In 2018, the cost of dirty air equated to 6.6 percent of Chinese GDP, 5.4 percent of India's GDP and 3 percent of US's GDP [1]. The economic burden of air pollution is shown as Fig. 1.

Decoupling economic growth from environmental pollution to achieve green development is the only way to deal with this dilemma. China has formulated a great plan for this. The Chinese government has issued the air pollution prevention and control action plan, which puts forward 10 key actions and 35 specific measures on air quality management. Including industrial structure upgrading, energy structure adjustment, point source and non-point source pollution control, management mechanism and safeguard measures [3]. The Chinese government clearly stated in the plan of the "energy production and consumption revolution strategy (2016-2030)" that the proportion of natural gas consumption and non-fossil energy consumption will be increased to about $15 \%$ and $20 \%$ respectively by 2030 [4]. To achieve these goals, China has adopted a policy of curbing the consumption of highly polluting fossil

\section{The Economic Burden Of Air Pollution}

Economic costs of air pollution from fossil fuels

as a share of GDP in 2018

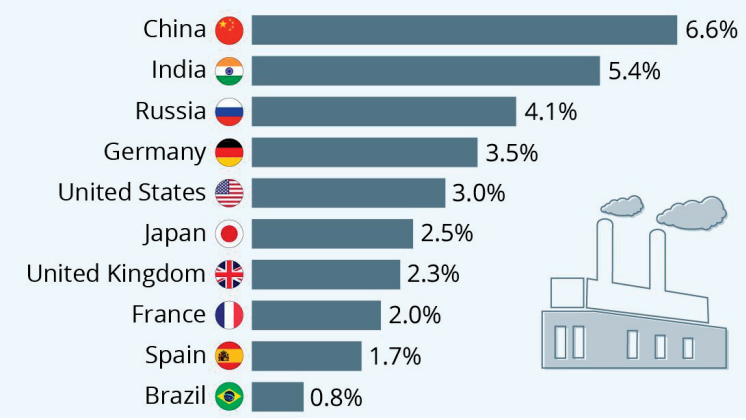

Fig. 1. The economic burden of air pollution [1]. energy while encouraging the consumption of clean energy. In addition, China is also actively adjusting its industrial policies, implementing industrial upgrades, promoting low-energy and low-emission production technologies, and reducing energy consumption intensity.

The essence of green development is to reduce the environmental load while maintaining the increase in total economic output, and even to "decouple" economic development from environmental pollution. Due to the characteristics of low pollution and low emissions, clean energy has been placed high hopes by the Chinese government in this decoupling process. However, on the one hand, many studies have shown that the stability, cost, and technological maturity of clean energy have obvious disadvantages compared with traditional fossil energy. In many cases, the use of clean energy will increase production costs and reduce production efficiency. So, what role does clean energy consumption play in decoupling economic growth from environmental pollution? Previous scholars have rarely done quantitative research on this topic. On the other hand, is the impact of clean energy on the decoupling of different regions heterogeneous? Because of the vast territory of China, the resource endowments, industrial structure, urbanization level, foreign investment preference, and environmental regulation level of different provinces vary greatly. The economic development models of various provinces are also completely different. Some choose to give priority to economic development, and some choose to give priority to environmental protection. These differences will cause the flow of capital, manpower, industry and other factors among different regions. This will cause the decoupling effect of economic growth and environmental pollution in various regions to diverge. Therefore, it is necessary to study the trend and differentiation of the decoupling effect between economic growth and environmental pollution, and the impact of clean energy consumption on decoupling in this context.

To improve the research in this field. Based on the Tapio decoupling theory, this paper calculates the decoupling index of economic growth and environmental pollution in 30 provinces and cities in China and in eastern, central and western China. Secondly, this article describes the decoupling characteristics of spatiotemporal coupling, and uses a spatial model to analyze its spatial aggregation and spatial heterogeneity. Finally, based on the spatial Durbin model, this paper quantitatively analyzes the impact of clean energy consumption on the decoupling effect of comprehensive environmental pollution, $\mathrm{SO}_{2}$ (Sulfur Dioxide) emissions, NOx (Oxynitride) emissions, DS (dust and smoke) emissions and economic growth.

The research on Environmental economy started from Environmental Kuznets Curve (EKC)in China. Scholars initially studied whether there is EKC between the level of China's economic development 
and environmental pollution [5, 6]. Later, decoupling analysis began to be applied to analyze the relationship between economic growth and environmental pollution. The Organization for Economic Cooperation and Development (OECD) first proposed the decoupling theory in 2002, which is mainly used to analyze the relative relationship between economic development and resource consumption [7]. Then, the scholar Tapio constructed the decoupling elasticity coefficient and classified the types when studying the development status and carbon dioxide emissions of the European transportation industry from 1970 to 2001 [8]. Since then, this model has been used by more and more scholars to analyze economic growth, carbon emissions, and air pollutant emissions $[9,10]$.

However, a single interactive relationship cannot explain the internal connection between economic growth and environmental pollution. Some scholars have evaluated the decoupling state of economic growth and environmental pollution and its driving factors from the perspective of decoupling analysis and factor decomposition. They initially combined the Tapio's model with the LMDI model. It is applied to the coupling analysis of economic growth and carbon emissions and to decompose the influencing factors of carbon emissions [11, 12]. Subsequently, the Tapio model was further expanded to analyze a variety of socio-economic driving factors. Wu et al. (2019) [10] combined the Tapio's elastic analysis method, modified the gravity model, social network analysis (SNA), secondary distribution process (QAP) regression and LOGIT model, and they explored the network effect of the decoupling between industrial waste gas emissions and industrial value added.

Liu et al. (2020) [13] proposed a combined model based on Tapio decoupling model, KAYA identity and LOG-MEAN DIVISIA index, and decomposed the impact of urbanization into four related factors. They used the method of comparative analysis to investigate the similarities and differences of urbanization-related factors that affect the decoupling state of logistics energy consumption and economic growth. Wang et al. (2019) [14] used the Tapio model, JOHANSEN co-integration theory and Granger causality test to study the impact of urbanization and industrialization on the decoupling of China's economic growth and carbon emissions. Dong et al. (2019) [15], Dong et al. (2020) [16] used GTWR to study the temporal and spatial heterogeneity of factors that affect the decoupling between economic growth and carbon emissions/pollutant emissions.

In addition to the diversity of research methods, research perspectives are also gradually diversified. Asumadu et al. (2019) [17] used PRAI-WINSTEN and COCHRANE-ORCUTT regression models to study the relationship between pollution and economic development during the transition from polluted energy to clean energy. The author believes that decoupling energy from economic growth can encourage Clean energy transformation. Chovancova et al. (2020) [18] proposed a cross-country comparison of the decoupling between economic growth and resources (energy consumption) and the decoupling between economic growth and environmental impact (greenhouse gas emissions), and found that the increase in renewable energy is coupled with most country's economic growth.

Another part of scholars does quantitative analysis from the perspective of decoupling effort index, studying the decoupling effort in different regions and the degree of influence of each factor on decoupling $[12,16,19,20]$. However, only a few researchers study the relationship between economic growth and environmental load from a spatial perspective. Yuan et al. (2019) [21] studied the driving factors of household carbon emissions from a spatial perspective, and studied the decoupling between "scale" effect (population, per capita income) and "effort" effect (emission factors, energy consumption structure and energy consumption intensity).

In summary, the current research has the following shortcomings: (1) Most scholars study carbon emissions rather than environmental pollutants. The research on environmental pollution only separately studies the coupling relationship between different types of pollutants and economic growth, while ignoring the correlation between pollutants. This will cause the conclusion to be underrepresented. (2) There is insufficient research on the spatial heterogeneity of decoupling and the spatial effect of decoupling. Few researchers combine the spatial econometric model with the Tapio's model to study economic growth and environmental pollution, so that the spatial characteristics of the decoupling between economic growth and environmental pollutants have not been fully explored. (3) There is insufficient research on the role of clean energy consumption in the decoupling between economic growth and environmental pollutants. Few scholars have quantitatively studied the impact of clean energy consumption on the decoupling of economic growth and environmental pollutants.

Compared with the existing research, the main contributions of this paper are as follows: (1) The comprehensive evaluation index of the three major pollutants $\mathrm{SO}_{2}$ (sulfur dioxide), NOx (oxynitride), DS (dust and smoke) has been constructed. This paper studies the decoupling effect between economic growth and environmental pollution in 30 provinces and cities in China from the provincial level and the eastern, central and western regions. (2) This paper uses the decoupling model to calculate the decoupling index between economic growth and environmental pollution in 30 provinces and cities in China. Combined with the spatial econometric model, the spatial aggregation and spatial heterogeneity of decoupling effects are analyzed. (3) This paper uses a spatial econometric model to quantify the impact of clean energy consumption on the decoupling between comprehensive environmental pollution, $\mathrm{SO}_{2}$ emissions, NOx emissions, DS emissions 
and economic growth. (4) In addition, this article also analyzes the impact of foreign direct investment (FDI), energy consumption per unit GDP (ECPG), environmental regulation (ER), industrial structure (IS) and urbanization rate (UR) on the decoupling between environmental pollution and economic growth.

\section{Materials and Methods}

\section{Data Sources}

This article selects the panel data of 26 provinces and 4 municipalities in China from 2011 to 2017 as the research sample (due to the availability and completeness of the data, this article excludes Tibet, Macau, Hong Kong and Taiwan). The data comes from "China Statistical Yearbook", "China Energy Statistical Yearbook" and "China Environment Yearbook". See Table 1 for descriptive statistics of variables.

\section{Decoupling Elasticity Coefficient Model}

The Organization for Economic Cooperation and Development (OECD) first proposed the decoupling theory in 2002, which is mainly used to analyze the relationship between economic development and resource consumption. However, the index system it constructed is very sensitive to the base period of economic development and resource consumption. The results and conclusions calculated from different base periods are very different, so the guiding significance is not great. This article refers to Tapio (2005) [8], constructs the decoupling elasticity index and classifies it. The elasticity index e (elasticity) calculation method is as follows:

Table 1. Descriptive Statistics of variables.

\begin{tabular}{|c|c|c|c|c|}
\hline Variable & Mean & Std.Dev & Min & Max \\
\hline eNOx & 6.41 & 4.59 & 0.526 & 56.866 \\
\hline $\mathrm{eDS}$ & 11.577 & 3.564 & 0.23 & 26.037 \\
\hline $\mathrm{eSO}_{2}$ & 11.676 & 3.211 & 0.99 & 32.038 \\
\hline $\mathrm{eCP}$ & 8.229 & 3.482 & 0.296 & 39.958 \\
\hline $\mathrm{CEC}$ & 63.059 & 46.944 & 3.18 & 237.69 \\
\hline FDI & 0.49 & 0.463 & 0.079 & 2.253 \\
\hline ECPG & 1.234 & 0.778 & 0.435 & 4.046 \\
\hline ER & 4582.5 & 6683.91 & 84 & 45140 \\
\hline UR & 0.571 & 0.122 & 0.364 & 0.896 \\
\hline IS & 0.447 & 0.083 & 0.19 & 0.577 \\
\hline
\end{tabular}

$$
\mathrm{e}_{i t}=\frac{\Delta \mathrm{P}}{\Delta \mathrm{Y}}=\frac{\left(\mathrm{P}_{\mathrm{i}, \mathrm{t}+1}-\mathrm{P}_{\mathrm{i}, \mathrm{t}}\right) / \mathrm{P}_{\mathrm{i}, \mathrm{t}}}{\left(\mathrm{Y}_{\mathrm{i}, \mathrm{t}+1}-\mathrm{Y}_{\mathrm{i}, \mathrm{t}}\right) / \mathrm{Y}_{\mathrm{i}, \mathrm{t}}}
$$

Among them, $P_{t}$ represents the pollutant emissions during the t period, $Y_{t}$ represents the economic output during the $t$ period, and in this article is GDP at a constant price.

The classification of the decoupling elasticity index in Tapio's model is shown in Fig. 2. In order not to overinterpret subtle changes, the coupled elasticity index is defined as between 0.8 and 1.2. The decoupling elasticity index can be divided into three categories: negative decoupling, decoupling, coupling. In which, negative decoupling could be divided into three categories: expansive negative decoupling $\left(\Delta \mathrm{P}>0, \Delta \mathrm{Y}>0, e_{i t}>1.2\right)$, weak negative decoupling $\left(\Delta \mathrm{P}<0, \Delta \mathrm{Y}<0,0<e_{i t}<0.8\right)$, strong negative decoupling $\left(\Delta \mathrm{P}>0, \Delta \mathrm{Y}<0, e_{i t}<0\right)$. Decoupling could be divided into three categories: strong decoupling $\left(\Delta \mathrm{P}<0, \quad \Delta \mathrm{Y}>0, e_{i t}<0\right)$, weak decoupling $(\Delta \mathrm{P}>0, \Delta \mathrm{Y}>0,0$ $\left.<e_{i t}<0.8\right)$, recessive decoupling $\left(\Delta \mathrm{P}<0, \Delta \mathrm{Y}<0, e_{i t}>1.2\right)$. Coupling could be divided into two categories: expansive coupling $\left(\Delta \mathrm{P}>0, \Delta \mathrm{Y}>0,0.8<e_{i t}<1.2\right)$, recessive coupling $\left(\Delta \mathrm{P}<0, \Delta \mathrm{Y}<0,0.8<e_{i t}<1.2\right)$.

\section{Spatial Econometric Models}

Spatial autocorrelation is described by the global Moran index, the calculation method is shown as follows:

$$
\begin{aligned}
& \text { Moran's Iglobal }=\frac{\sum_{\mathrm{i}=1}^{\mathrm{n}} \sum_{\mathrm{j} \neq \mathrm{i}}^{\mathrm{n}} \mathrm{w}_{\mathrm{ij}}\left(\mathrm{x}_{\mathrm{i}}-\overline{\mathrm{x}}\right)\left(\mathrm{x}_{\mathrm{j}}-\overline{\mathrm{x}}\right)}{\sigma^{2} \sum_{\mathrm{i}=1}^{\mathrm{n}} \sum_{\mathrm{j} \neq \mathrm{i}}^{\mathrm{n}} \mathrm{w}_{\mathrm{ij}}} \\
& =\frac{\sum_{\mathrm{i}=1}^{\mathrm{n}} \sum_{\mathrm{j} \neq \mathrm{i}}^{\mathrm{n}} \mathrm{w}_{\mathrm{ij}}\left(\mathrm{x}_{\mathrm{i}}-\frac{1}{\mathrm{n}} \sum_{\mathrm{i}=1}^{\mathrm{n}} \mathrm{x}_{\mathrm{i}}\right)\left(\mathrm{x}_{\mathrm{j}}-\frac{1}{\mathrm{n}} \sum_{\mathrm{i}=1}^{\mathrm{n}} \mathrm{x}_{\mathrm{i}}\right)}{\frac{1}{\mathrm{n}} \sum_{\mathrm{i}=1}^{\mathrm{n}}\left(\mathrm{x}_{\mathrm{i}}-\frac{1}{\mathrm{n}} \sum_{\mathrm{i}=1}^{\mathrm{n}} \mathrm{x}_{\mathrm{i}}\right)^{2} \sum_{\mathrm{i}=1}^{\mathrm{n}} \sum_{\mathrm{j} \neq \mathrm{i}}^{\mathrm{n}} \mathrm{w}_{\mathrm{ij}}}
\end{aligned}
$$

However, the global Moran index cannot detect the local correlation, so it is necessary to quote the local Moran index, the local Moran index is expressed in Eq. (3):

$$
\text { Moran's I I local }=\frac{n\left(x_{i}-\bar{x}\right) \sum_{j=1}^{n^{n}} W_{i j}\left(x_{j}-\bar{x}\right)}{\sum_{i=1}^{n}\left(x_{i}-\bar{x}\right)^{2}}
$$

Spatial weight matrix is the core component of spatial analysis model. The spatial adjacency weight matrix is a spatial weight matrix that reflects the spatial adjacency relationship. It can be set as follows: There is a significant mutual influence relationship between the areas that border each other, and the areas that are not bordered have no significant interaction. The spatial adjacency weight matrix can more closely reflect the spatial relationship of development indicators between provinces and municipalities. Therefore, this article introduces the spatial adjacency 


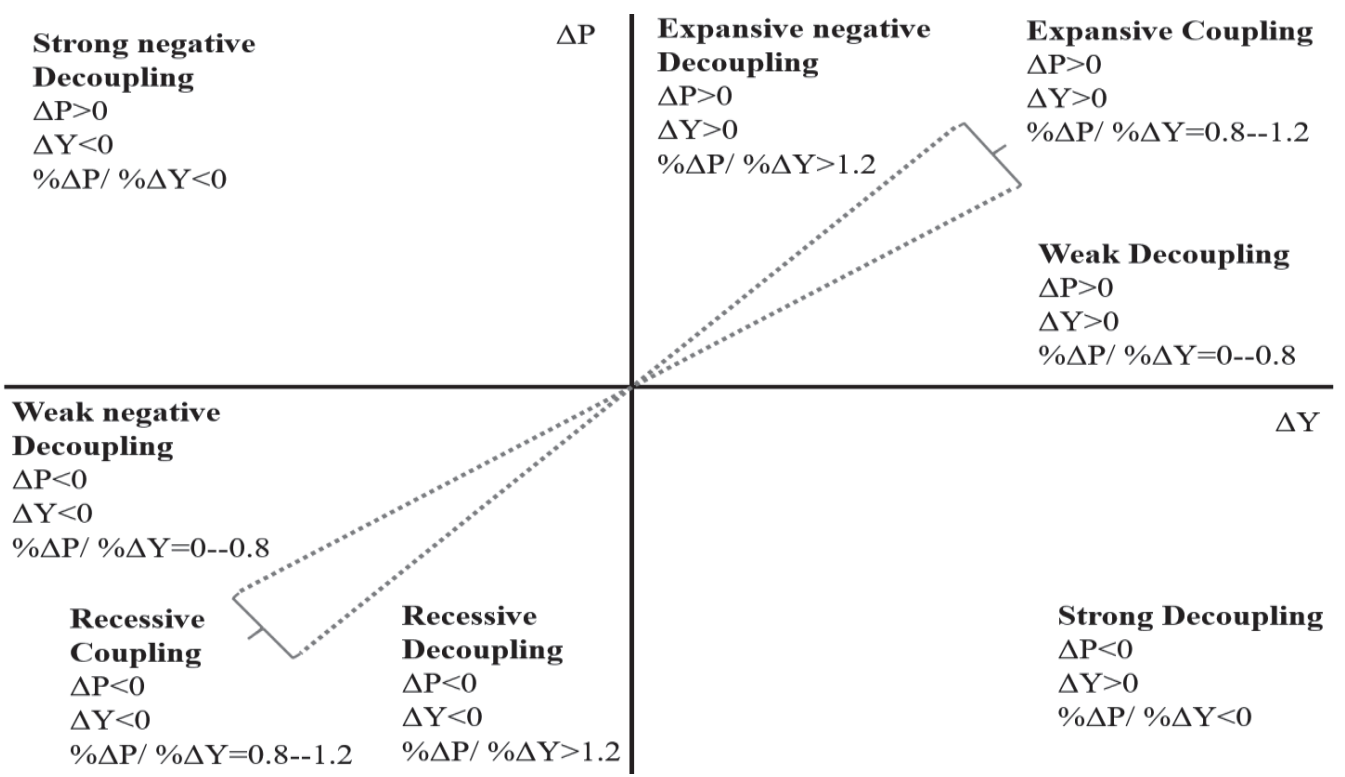

Fig. 2. Decoupling elasticity index and its classification.

weight matrix of each province and municipality to make the spatial relationship of development indicators concrete.

$$
\mathrm{W}_{\mathrm{ij}}^{\mathrm{A}}=\left\{\begin{array}{c}
1, \text { if province } \mathrm{i} \text { and } \mathrm{j} \text { is adjacent } \\
0, \text { if province } \mathrm{i} \text { and } \mathrm{j} \text { is not adjacent }
\end{array}\right.
$$

\section{Spatial Durbin Model}

When we analyze and study issues related to regional characteristics, we often regard each region as an independent individual to study the relationship between variables. There are often spatial correlations and spatial dependencies between regions and cannot be ignored. Therefore, we need to use the spatial measurement model to study the relationship between variables based on considering the spatial correlation and dependence between variables. The spatial Durbin model (SDM) integrates the advantages of both the spatial error model and the spatial lag model. It comprehensively considers the spatial lag factors of important variables such as explanatory variables and explained variables. SDM contains both the dependent variable and independent variable spatial lag term. SDM is usually employed as the starting point for analysis, and its manifestation can be expressed as Eq. (5).

$$
\mathrm{e}_{-} \mathrm{P}=\beta \mathrm{X}+\rho \mathrm{We} \_\mathrm{P}+\theta \mathrm{WX}+\varepsilon
$$

Eq. (5) represents the spatial Durbin model of the decoupling elasticity coefficient between economic growth and environmental pollution, where e_P is the explained variable in this article, which represents the decoupling elasticity index of economic growth and environmental pollution. The decoupling elasticity index studied in this paper includes four types: eCP,
$\mathrm{eSO}_{2}$, eNOx, eDS, which correspond to the decoupling elasticity index between pollutants $\mathrm{CP}, \mathrm{SO}_{2}, \mathrm{NOx}, \mathrm{DS}$ and economic growth. $\beta$ represents the coefficient of the variable. $X$ represents the $n \times k$ combination matrix of exogenous explanatory variables. The core explanatory variable is clean energy consumption (CEC). In addition, control variables that affect the flexibility of decoupling between economic growth and environmental pollution are selected, including ECPG (Energy Consumption Per GDP), GDP, ER (environment regulation), and FDI (Foreign Direct Investment), IS (Industrial Structure), UR (Urbanization Rate). $\rho$ is the spatial autoregressive coefficient. $\rho \mathrm{We}$ P represents the spatial lag term of decoupling elasticity between economic growth and industrial sulfur dioxide. $\theta$ is the spatial overflow coefficient. $\theta \mathrm{WX}$ is the spatial lag of the explanatory variable. $\mathrm{W}$ is an $\mathrm{n} \times \mathrm{n}$ spatial weight matrix. $\varepsilon$ represents a random error term that follows a normal distribution.

However, considering that the decoupling elasticity index e_P has positive and negative values, this article refers to Xia et al. (2017) [22] and adopts the translation method of Eq. (6):

$$
\ln \mathrm{s}_{-} \mathrm{e}_{\mathrm{it}}=\ln \left(\ln \mathrm{e}_{\mathrm{it}}-\ln \left(\operatorname{int}\left(\mathrm{e}_{\mathrm{it}-\mathrm{min}}\right)\right)\right.
$$

Among them, int $\left(e_{i t-\min }\right)$ represents the integer of the minimum value of the decoupling elastic coefficient. $e_{i t}$ represents the original decoupling elastic coefficient. $s \_e_{i t}$ represents the decoupling elastic coefficient after translation.

\section{Direct and Indirect Spatial Impact}

In the spatial econometric model, the independent variable usually has an indirect effect (spatial spillover) on the dependent variable in the surrounding non-local 
areas. Spatial spillover effects include indirect spillover effects and direct spillover effects. The direct, indirect and total spatial effects have been estimated based on the estimated spatial regression coefficients [23, 24]. This further quantifies the spatial spillover effect of clean energy consumption and other explanatory variables on the decoupling of economic growth and environmental pollution. The direct and indirect spatial effects are determined according to the determined spatial correlation coefficient $\rho$. The matrix of the partial derivative differential equation of the explained variable $\mathrm{e} P \mathrm{P}$ with respect to the $\mathrm{K}$-th independent variable is shown in Eq. (7).

$$
\begin{aligned}
& {\left[\frac{\partial \mathrm{e}_{2} \mathrm{P}}{\partial \mathrm{X}_{\mathrm{ik}}} \ldots \frac{\partial \mathrm{e}_{\mathrm{X}} \mathrm{P}}{\partial \mathrm{X}_{\mathrm{Nk}}}\right]=\left[\begin{array}{ccc}
\frac{\partial \mathrm{e}_{-} \mathrm{P}}{\partial \mathrm{X}_{\mathrm{ik}}} & \cdots & \frac{\partial \mathrm{e}_{-} \mathrm{P}}{\partial \mathrm{X}_{\mathrm{nk}}} \\
\vdots & \ddots & \vdots \\
\frac{\partial \mathrm{e}_{-} \mathrm{P}_{\mathrm{n}}}{\partial \mathrm{X}_{\mathrm{ik}}} & \cdots & \frac{\partial \mathrm{e}_{-} \mathrm{P}}{\partial \mathrm{X}_{\mathrm{nk}}}
\end{array}\right]=(\mathrm{I}-\rho \mathrm{W})^{-1}} \\
& {\left[\begin{array}{cccc}
\beta_{\mathrm{k}} & \mathrm{w}_{12} \theta_{\mathrm{k}} & \cdots & \mathrm{w}_{1 \mathrm{n}} \theta_{\mathrm{k}} \\
\mathrm{w}_{21} \theta_{\mathrm{k}} & \beta_{\mathrm{k}} & \cdots: & \mathrm{w}_{2 \mathrm{n}} \theta_{\mathrm{k}} \\
\cdots & \cdots & \cdots & \cdots \\
\mathrm{w}_{\mathrm{n} 1} \theta_{\mathrm{k}} & \mathrm{w}_{\mathrm{n} 2} \theta_{\mathrm{k}} & \cdots & \beta_{\mathrm{k}}
\end{array}\right]}
\end{aligned}
$$

The above equation defines the average value of the sum of the matrix element values on the right side as a direct effect, and the average value of all row and column element sums of off-diagonal elements is an indirect effect, reflecting the influence of other regional independent variables on regional dependent variables.

\section{Variable Interpretation and Hypothesis}

\section{Explained Variable}

The explained variable in this paper is the elastic coefficient of decoupling between economic growth and environmental pollution. Among the variables measuring the degree of environmental pollution, the most representative one is the emission of air pollutants. Scholars generally use $\mathrm{SO}_{2}$ (sulfur dioxide), NOx (Oxynitride), DS (dust and smoke) to measure air pollution. Considering that each pollutant has its own limitations, the use of a certain pollutant indicator alone cannot reflect the true situation of environmental pollution. Therefore, this article reduces the dimensions of these indicators to find a comprehensive pollution indicator, to make an objective and comprehensive evaluation of air pollution as far as possible.

This article draws on the method of Liu et al. (2015) [25] for processing, and then obtains the index weights of the three pollutants of $\mathrm{SO}_{2}, \mathrm{NOx}$, and DS, and finally calculates the comprehensive pollution $(\mathrm{CP})$ :

$$
C P_{i t}=\sum_{i=1}^{n} w_{i t} * X_{i t}
$$

Among them: $w_{i t}$ is the weight of each pollutant, and $X_{i t}$ is the type of pollutant.

\section{Explanatory Variables and Hypothesis}

The explanatory variable of this article is clean energy consumption (CEC). When environmental pollution becomes an obstacle in the process of economic growth, the development of clean energy is one of the main strategies to promote sustainable economic development. Although the cost of clean energy at this stage is higher than that of traditional high-pollution fossil energy, in the long run, the benefits of clean energy to the society and economy will exceed the low production cost of high-pollution energy [26]. Since the consumption of clean and renewable energy such as wind energy, solar energy, and biomass energy is relatively small, and the data is difficult to obtain, this paper refers to Li et al. (2020) [27] and selects natural gas as the representative variable of clean energy.

Hypothesis 1: Clean energy can effectively promote the decoupling between economic growth and comprehensive pollutant emissions.

Hypothesis 2: Clean energy can effectively promote the decoupling between economic growth and $\mathrm{SO}_{2}$ emissions.

Hypothesis 3: Clean energy can effectively promote the decoupling between economic growth and NOx emissions.

Hypothesis 4: Clean energy can effectively promote the decoupling between economic growth and DS comprehensive pollutants.

\section{Control Variables}

(1) Environmental Regulation (ER). Due to the existence of industry heterogeneity, different types of environmental regulations have heterogeneity in the environmental impact of different industries. The establishment of environmental regulations should avoid the uniform adoption of static standards and blindly increasing the intensity of supervision. According to the characteristics and reality of different industries, flexible and dynamic regulatory standards and multiple regulatory methods should be adopted [28]. Therefore, this article refers to the environmental indicator setting of Zhu et al. (2020) [29], and uses the number of environmental pollution penalties as the proxy variable for environmental regulations in various regions.

(2) Foreign Direct Investment (FDI). The pollution paradise hypothesis holds that there are differences in the intensity of environmental regulations in different regions. To avoid the increase in production costs caused by the increase in the intensity of domestic environmental regulations, pollution-intensive companies tend to move their industries to countries or regions with relatively loose environmental regulations. This has led to increased environmental pollution in the host country or host region, and deterioration in environmental quality [30]. Therefore, the increase in the intensity of foreign direct investment may inhibit the decoupling between economic growth 
and environmental pollution. This article uses the proportion of total foreign direct investment in GDP as an indicator to measure the level of foreign direct investment in a province or region. However, due to the difference between nominal GDP and actual GDP, this article uses the GDP of each province and city in 2000 as the basis to calculate the GDP deflator to obtain GDP at constant prices.

(3) Industrial structure (IS): As an important link between human economic activities and air quality, industrial structure is a key factor in solving the contradiction between economic development and the environment [31]. The secondary industry is an important subject that causes environmental pollution emissions. If the proportion of the secondary industry in a country or region is too high, environmental pollution may increase, which will inhibit the decoupling between economic growth and environmental pollution. This article uses the proportion of the secondary industry to characterize the industrial structure of a province or region.

(4) Energy consumption per unit of GDP (ECPG): As China's economy is highly dependent on fossil energy and environmental protection measures are not perfect, environmental pollution is closely related to energy consumption [32]. Industries with high energy consumption are more polluting than industries with low energy consumption. The increase in energy consumption per unit of GDP may inhibit the decoupling between economic growth and environmental pollution. Therefore, this paper chooses energy consumption per unit of actual GDP as the indicator.

(5) Urbanization rate (UR): Urbanization means the agglomeration of population, the improvement of economic consumption level, and the increase of energy consumption. This is often accompanied by an increase in pollution levels. The relationship between urbanization and environmental pollution is nonlinear, and there is a comprehensive relationship. The role of urbanization in promoting environmental pollution has become more and more obvious, but this promotion has weakened as the proportion of the tertiary industry increases [33]. This paper uses the proportion of the urban population in the total population of the region at the end of the year to measure the level of urbanization.

\section{Results and Discussion}

\section{Decoupling Analysis}

According to Eq. (1), this paper separately measured the Tapio decoupling elastic coefficients between comprehensive pollutant emissions (CP), NOx, DS, $\mathrm{SO}_{2}$ and the economic growth in eastern, central and western China. At the same time, this article defines the decoupling status in different years based on economic growth and environmental pollutant emission growth, as shown in Table 2.
The economic growth of eastern, central, and western China presents different trends of differentiation, and environmental pollution also has different characteristics to a certain extent. The elasticity of decoupling between economic growth and environmental pollution in different regions and in different years is quite different.

Eastern region: From 2012 to 2017, while maintaining economic growth in the eastern region, the emission of pollutants $\mathrm{SO}_{2}$ and $\mathrm{NOx}$ continued to decrease. The elastic coefficients of decoupling between $\mathrm{SO}_{2}, \mathrm{NOx}$ and economic growth are all negative, and they are all in a strong decoupling state. However, in 2013 and 2014, the emissions of DS rebounded, which led to the weak decoupling of DS and economic growth in 2013 and the expansive negative decoupling in 2014. Along with economic growth, the increase in DS emissions has led to a slight increase in comprehensive pollutant emissions in the eastern region. This caused a weak decoupling between $\mathrm{CP}$ and economic growth in 2014.

Central China: The decoupling between $\mathrm{SO}_{2}$, NOx and economic growth in the central region is the same as that in the eastern region. However, the central region also encountered similar problems with the eastern region, that is, DS emissions increased inversely in 2013 and 2014. This leads to weak decoupling and expansive negative decoupling between DS and economic growth.

Western region: The decoupling trend between $\mathrm{SO}_{2}$ and economic growth in the western region is the same as that in the eastern and central regions. However, DS emissions in the western region increased during 2012-2014. This leads to weak decoupling between DS and economic growth, even to strong negative decoupling. This led to a weak decoupling between comprehensive environmental pollution and economic growth in the western region in 2014.

However, China has a vast territory, and the differences between provinces and cities are far greater than those in the eastern, central, and western regions. Therefore, the decoupling elasticity and decoupling state between various pollutants and economic growth also have spatial heterogeneity and spatial effects. This article chooses one year as the calculation period. The decoupling status of 30 provinces and cities over the years is shown in Fig. 3 .

In general, with the improvement of the quality of economic growth, China's provinces and cities have made more significant achievements in green development. The specific manifestation is that more and more provinces and cities have reached a strong decoupling state of decoupling between economic growth and environmental pollution. The comprehensive pollutant emissions have fallen while maintaining economic growth. Among them, on the one hand, the proportion of provinces in strong decoupling in China increased from $66.7 \%$ to $76.7 \%$ from 2012 to 2017 . On the other hand, provinces in expansive coupling accounted for $20 \%$ in 2012 , and this proportion dropped 


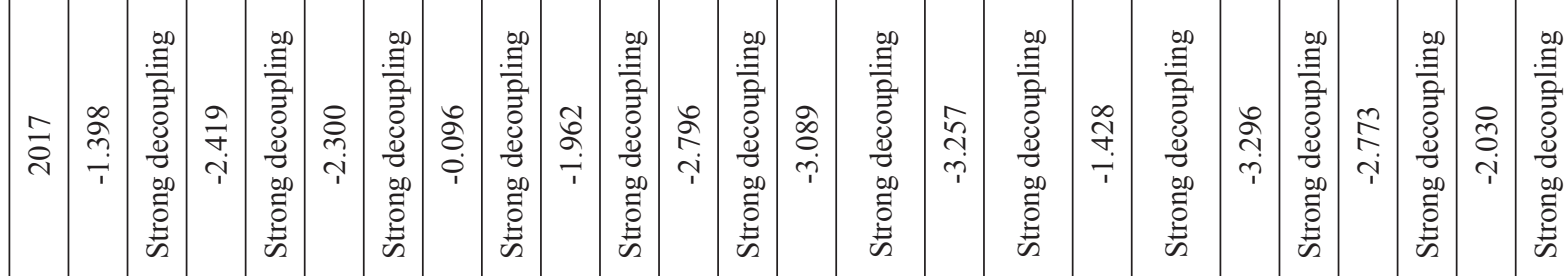

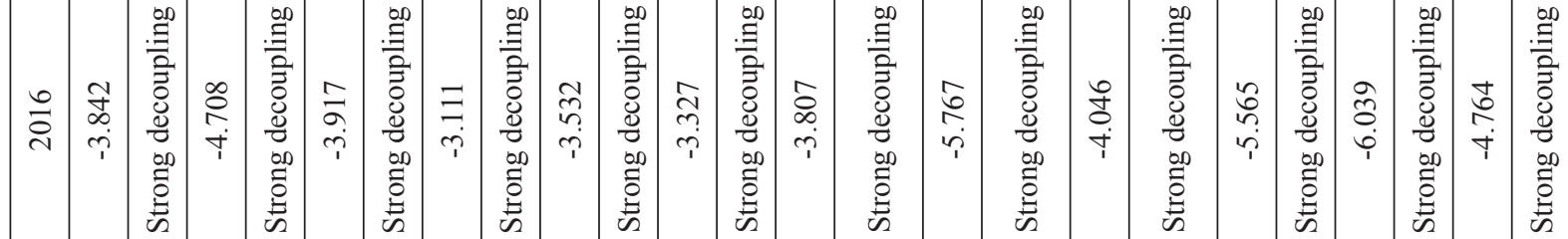

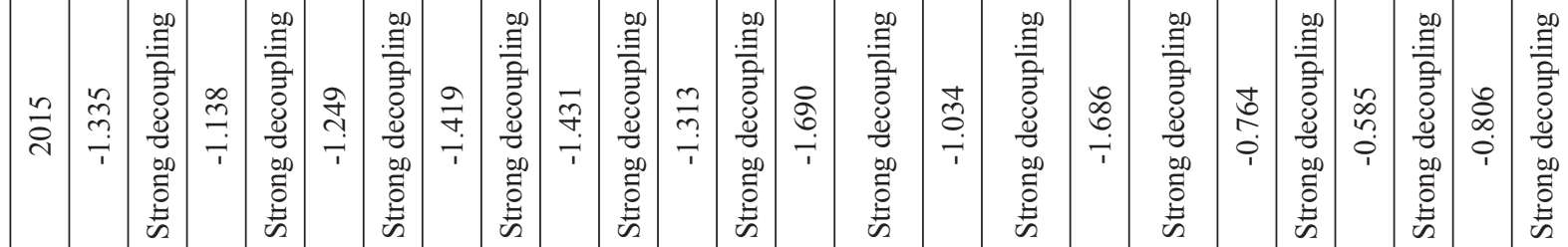

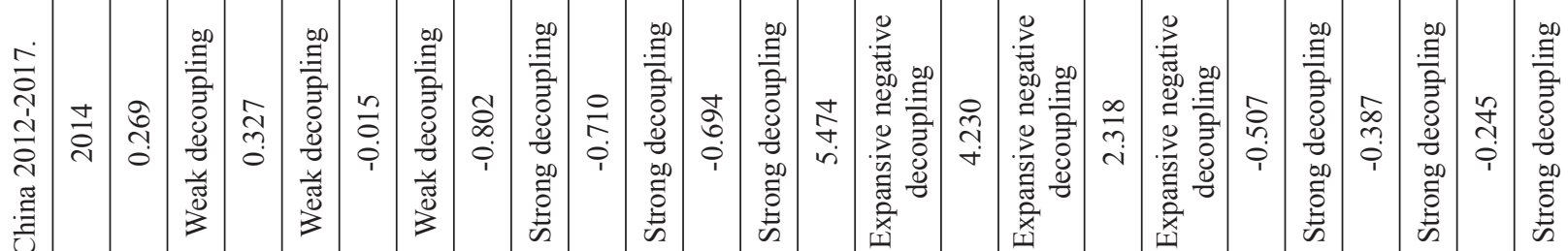

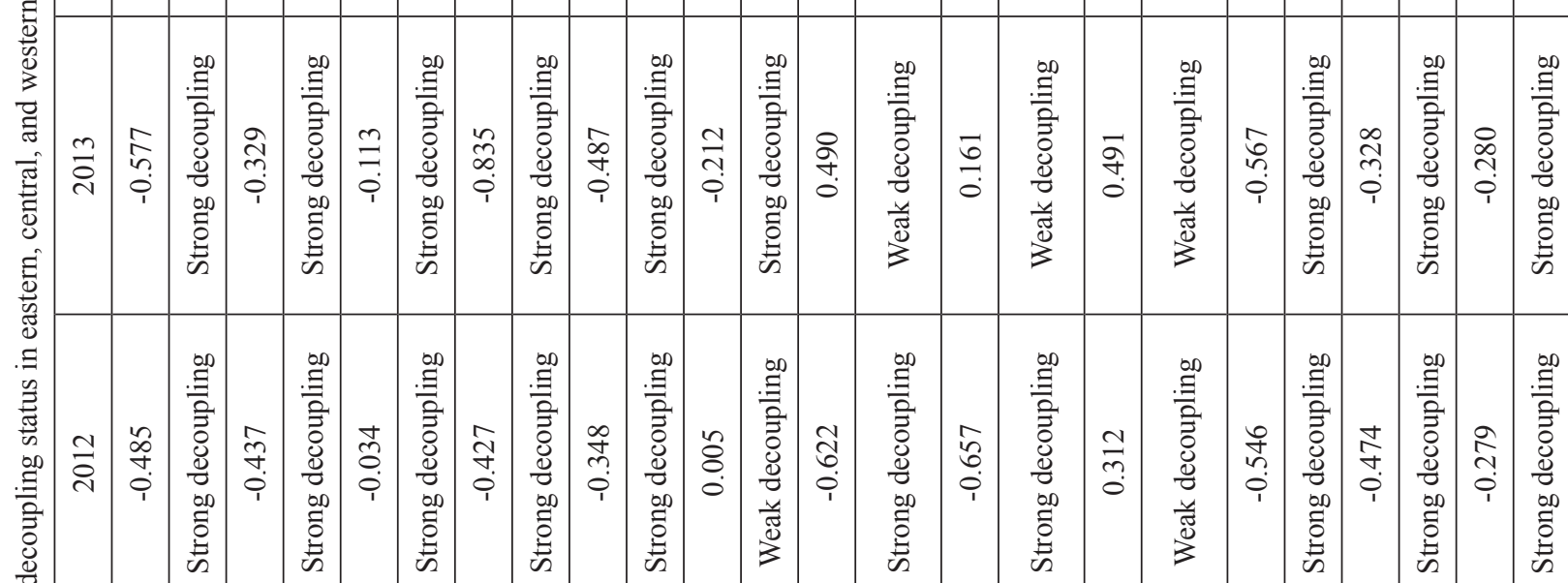
च

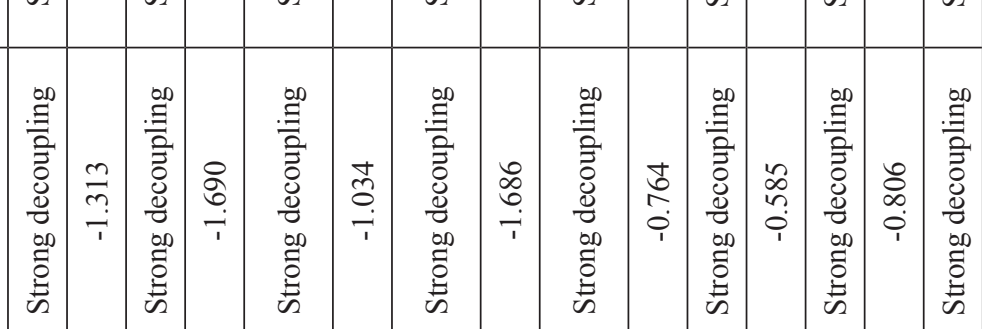

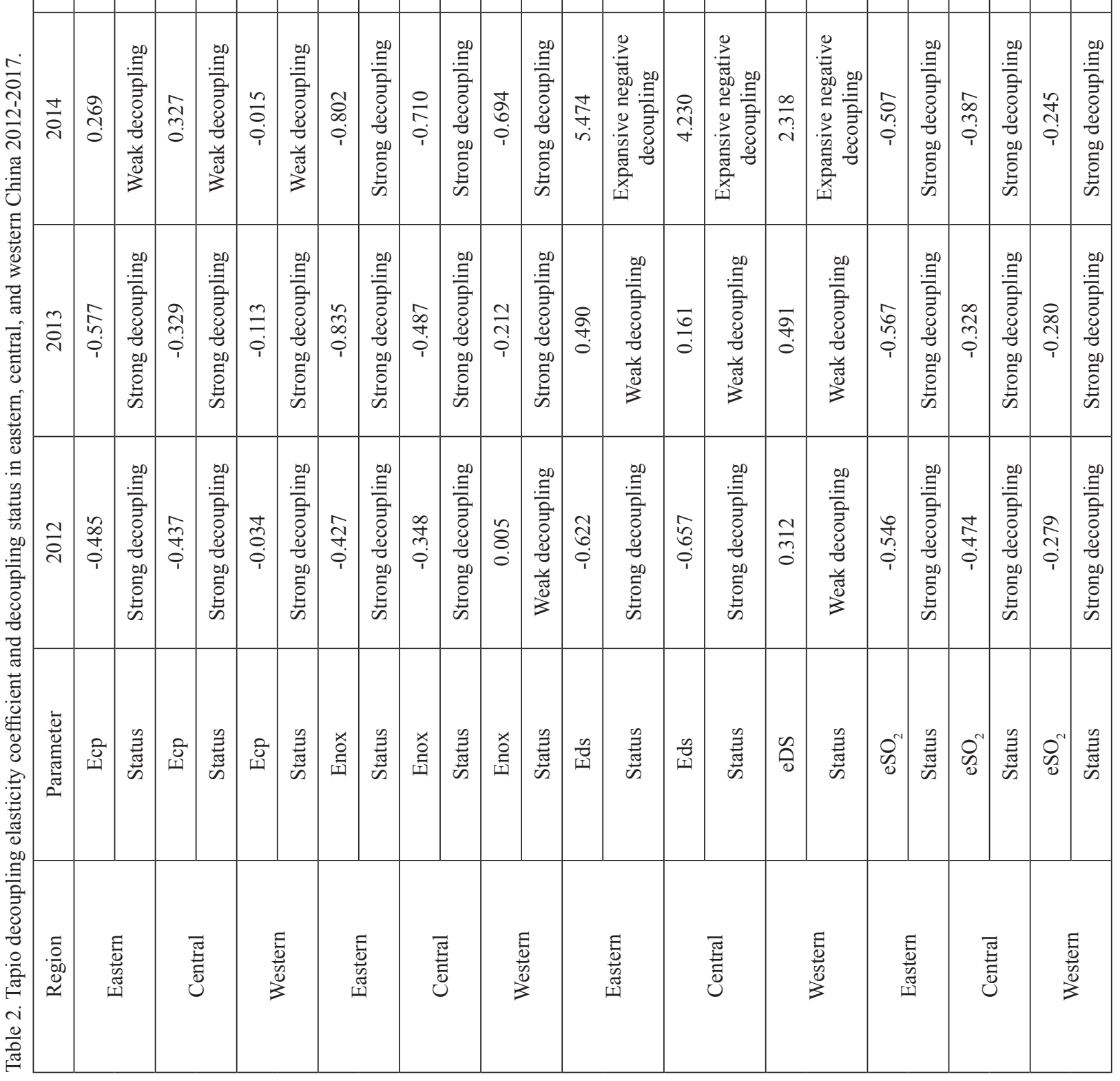



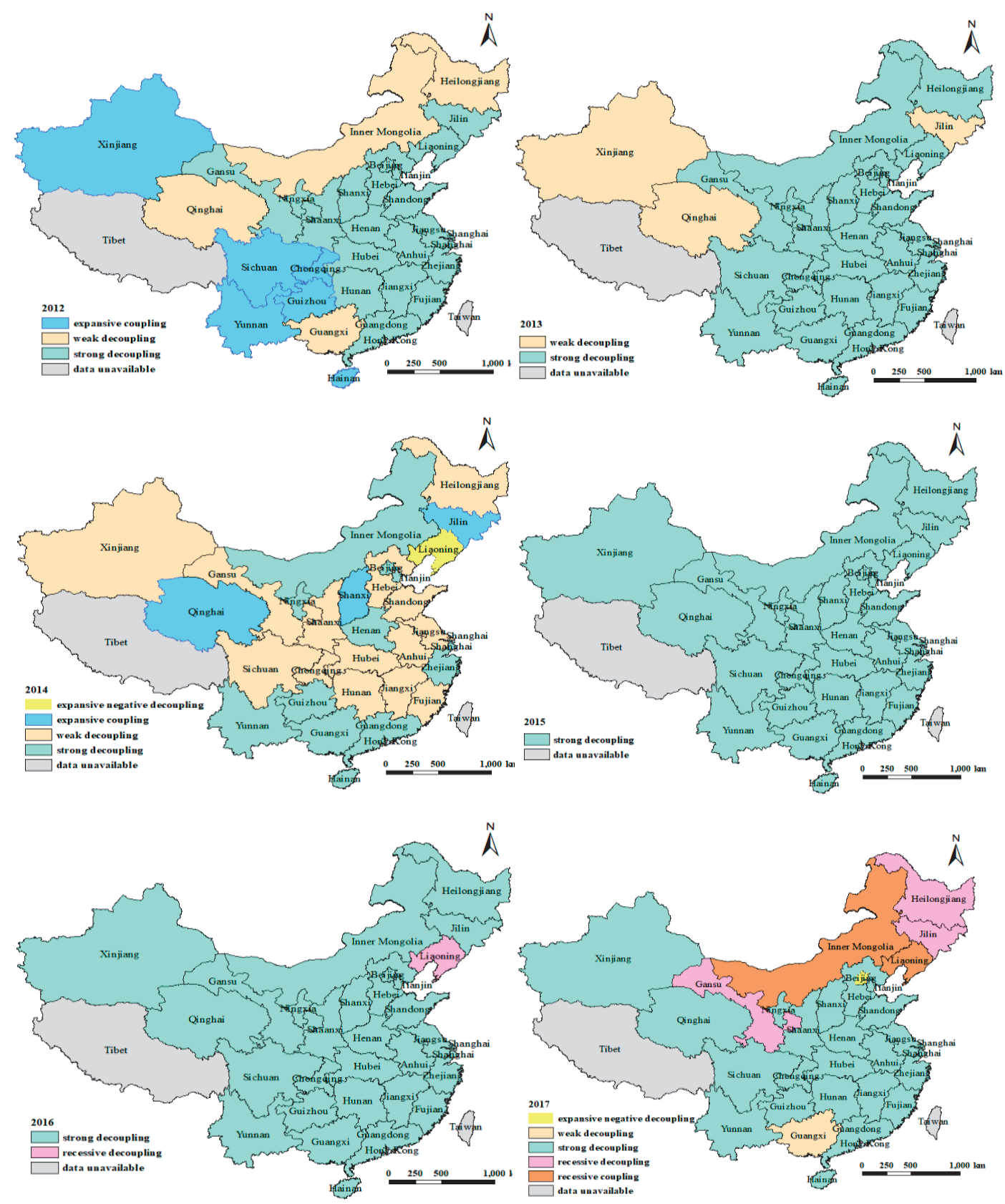

Fig. 3. Spatial distribution of decoupling status between economy growth and comprehensive pollution from 2012 to 2017.

to zero in 2017. The changing trend of the decoupling state is very satisfying. It shows that the economy has grown, but the environmental pollution has dropped. In the context of green development, the "decoupling" between China's economic growth and environmental pollution has replaced "coupling." However, economic growth has also brought obstacles to some regions. "Weak decoupling" or even "recessive coupling" appeared in some areas. The decoupling state shows obvious periodicity and spatial heterogeneity. The first type of regions, dominated by "strong decoupling", are mainly distributed in the southeast coast of China and some central provinces. They have been in a state of strong decoupling during the study period. The second type of region is in strong decoupling most of the time and weak decoupling for a small part of the time. Such areas mainly include Hubei, Hunan, Jiangxi, Shanxi, Guangxi, and Sichuan. The third type of regions fluctuates between decoupling and coupling, mainly including Gansu, Inner Mongolia, Liaoning, Jilin, and Heilongjiang. Such areas often have relatively backward industries and weak foundations for green development.

Obviously, the decoupling between economic growth and environmental pollution has significant spatial heterogeneity. In addition, different provinces in the east, middle and west have strong spatial connections. Therefore, this article will explore the spatial characteristics of the decoupling between economic growth and environmental pollution from 
the perspective of spatial correlation and spatial heterogeneity.

\section{Spatial Heterogeneity of Decoupling}

In this paper, the Moran index of the decoupling elasticity coefficient between the four environmental pollutants and economic growth in 30 provinces and cities is measured, and the results are shown in Table 3.

The results show that the Moran index has both positive and negative values. This means that there is a positive spatial correlation between the decoupling elastic coefficients in some time, that is, spatial aggregation. However, there is a negative spatial correlation between the decoupling elastic coefficients at certain times, namely spatial repulsion. Therefore, the decoupling between economic growth and environmental pollution in the central area may lead to decoupling in neighboring areas, or coupling in neighboring areas. This needs to be further empirically tested using the spatial measurement model in the following part.

This study uses ArcGIS software to calculate the local Moran index of decoupling elasticity, and draws the Local Indicators of Spatial Association (LISA) Cluster Maps, as shown in Fig 4. The local spatial autocorrelation of decoupling elasticity can be divided into four types: high-high, high-low, low-high, and lowlow. The local spatial aggregation state of decoupling elasticity presents a large spatial difference. In 2012, the spatial aggregation of decoupling elasticity was not significant, and the differences in the level of green development among provinces were not particularly large. After that, differentiation began. In 2013, Xinjiang, Qinghai, Gansu, and Ningxia in the northwest region formed "high-high" clusters. The trend of "coupling" between economic growth and pollution is greater than the trend of "decoupling", and the level of green development in Northwest China has begun to lag other regions. At the same time, "low-low" clusters were formed in Beijing, Hebei, Jiangsu, and Shanghai. In contrast, such a pattern has not appeared in the west. This trend of decoupling and differentiation reached its peak in 2015. Hubei and Sichuan in the central part have become "high-high" clusters, while Beijing and Hebei are still "low-low" clusters. This has a lot to do with the different clean energy policies and industrial development policies adopted by various provinces. During this period, the clean energy policies of many eastern and central provinces played a key role. Since then, the "low-low" cluster center gradually moved south to Henan, while the "high-high" cluster center gradually moved north to Inner Mongolia. In the foreseeable future, the decoupling trend of eastern and southern provinces and the coupling trend of northwestern provinces will become more and more obvious.

\section{Analysis of Regression Estimation Results of Spatial Panel Model}

Table 4 shows the results of the spatial Durbin model. This model quantifies the impact of clean energy consumption (CEC) and other control variables and their spatial lag terms on the explanatory variables. The WALD and LR test results of $\mathrm{eSO}_{2}$ and eNOx showed that H0wald and HOLR were rejected at the 1\% significance level. The estimation results show that the spatial Durbin model is the best model for sample data.

Spatial spillover effect refers to the influence of spatial lag variables on dependent variables. But only by analyzing the coefficient of the spatial lag term, we cannot accurately know whether there is a real spatial spillover effect in clean energy consumption. Therefore, this paper also decomposes the impact of clean energy consumption (CEC) and other control variables on explanatory variables into direct spillover effects, indirect spillover effects, and total spillover effects, as shown in Table 5.

The results show that the regression estimation coefficients of CEC for eCP, $\mathrm{eSO}_{2}, \mathrm{eNOx}$, and eDS are all negative. Among them, the regression coefficients of $\mathrm{CEC}$ on eCP, $\mathrm{eSO}_{2}$, and eDS passed the significance test. Therefore, Hypothesis 1, 2 and 4 were confirmed. The increase in local clean energy consumption can

Table 3. The global Moran's I statistics of the decoupling elasticity between economy growth and environment pollution.

\begin{tabular}{|c|c|c|c|c|c|c|c|}
\hline Variables & statistics & 2012 & 2013 & 2014 & 2015 & 2016 & 2017 \\
\hline \multirow{3}{*}{$\mathrm{eCP}$} & Moran & 0.0993 & $0.156^{* * *}$ & $-0.107^{*}$ & $0.116^{*}$ & -0.0839 & $0.0906^{*}$ \\
\cline { 2 - 8 } & $\mathrm{Z}$ value & 1.053 & 2.57 & -0.303 & 0.640 & 0.281 & 0.525 \\
\hline \multirow{2}{*}{$\mathrm{eSO}_{2}$} & Moran & 0.0851 & $0.0984^{*}$ & $0.185^{* *}$ & $0.084^{*}$ & $-0.099^{*}$ & $0.220^{* * *}$ \\
\cline { 2 - 8 } & $\mathrm{Z}$ value & 1.070 & 1.223 & 2.085 & 1.118 & 0.235 & 2.418 \\
\hline \multirow{3}{*}{$\mathrm{eNOx}$} & Moran & $0.218^{* * *}$ & $0.168^{* *}$ & $0.197 * *$ & 0.0994 & 0.0705 & -0.0964 \\
\cline { 2 - 8 } & Z value & 2.335 & 1.887 & 2.078 & 0.493 & 0.432 & -0.806 \\
\hline \multirow{2}{*}{$\mathrm{eDS}$} & Moran & -0.114 & $-0.211^{* *}$ & $-0.211^{* *}$ & 0.0652 & 0.00746 & $0.284 * * *$ \\
\cline { 2 - 8 } & Z value & -0.726 & -1.614 & -1.614 & 1.305 & 0.504 & 2.927 \\
\hline
\end{tabular}




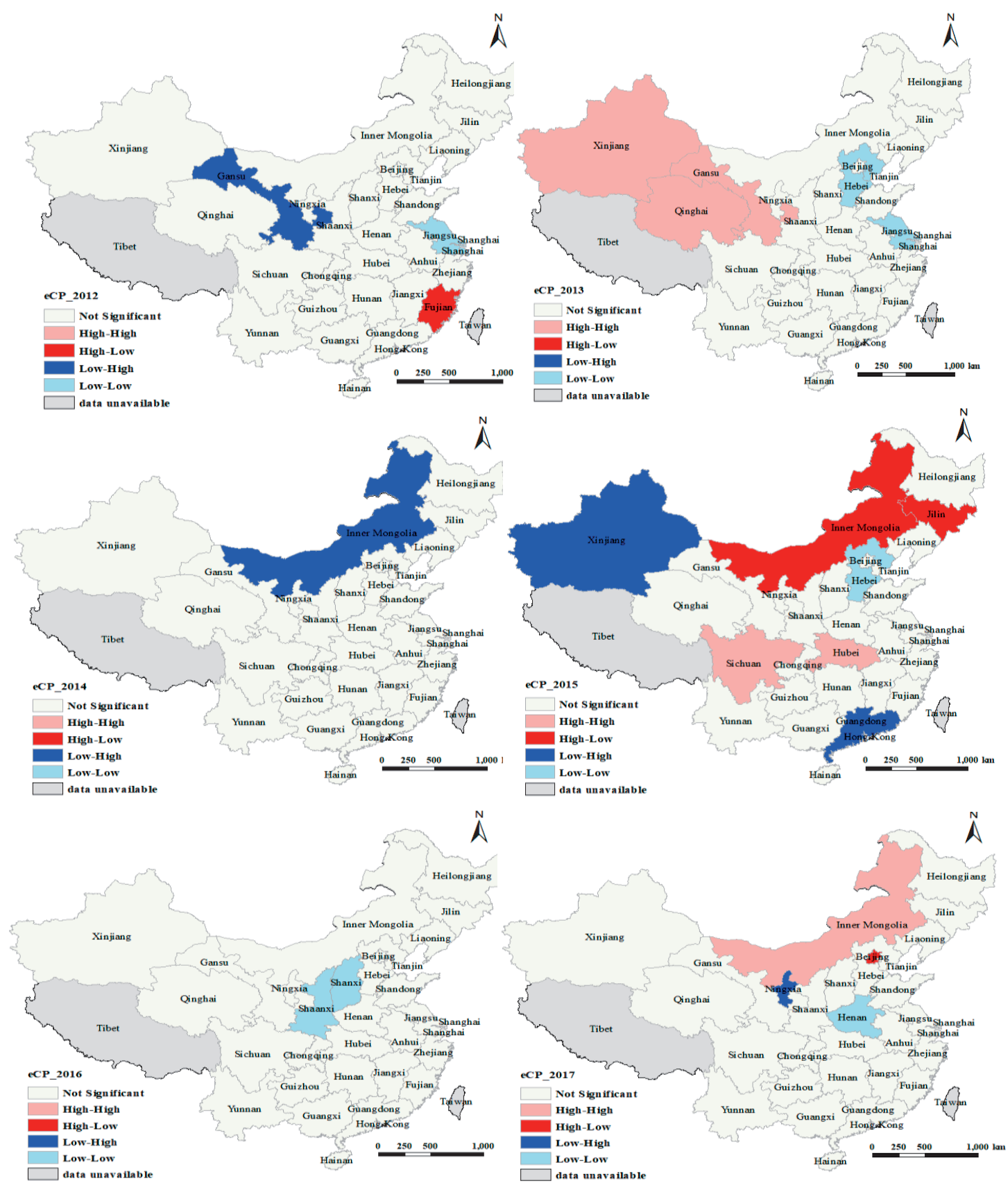

Fig. 4. Local indicators of spatial association (LISA) cluster maps for decoupling elasticity between comprehensive pollution and economic growth from 2012 to 2017.

significantly promote the decoupling between economic growth and comprehensive pollutant emissions, $\mathrm{SO}_{2}$ emissions, and DS emissions, which is consistent with the conclusions of Sarkodie et al. (2020) [34]. However, the lagging coefficient of clean energy consumption did not pass the significance test, indicating that the increase in local clean energy consumption has no significant impact on the decoupling between environmental pollution and economic growth in surrounding areas. Moreover, we refer to Pace et al. (2009) [24] to further decompose the effect of clean energy consumption. The direct effect is the average impact of clean energy consumption on the decoupling of local areas, and the indirect effect is the average impact of clean energy consumption on the decoupling of surrounding areas through spatial interaction. The total effect refers to the average impact of clean energy consumption on the decoupling of all regions. The regression coefficients of the direct, indirect and total effects of clean energy consumption on $\mathrm{eSO}_{2}$ are $-0.4359,0.0272$, and -0.4087 , respectively. The direct effect passed the $1 \%$ significance level test. At the same time, the regression coefficients of the direct effect, indirect effect, and total effect of clean energy consumption on eDS are $-0.6560,0.2983$, and -0.3577 , respectively, and the direct effect has passed the $1 \%$ significance level test. 
Table 4. Estimation results of the spatial Durbin panel models with spatial fixed effects.

\begin{tabular}{|c|c|c|c|c|}
\hline & $\operatorname{lneCP}$ & $\operatorname{lneSO}_{2}$ & lneNOx & lneDS \\
\hline \multicolumn{5}{|c|}{ Main } \\
\hline \multirow{2}{*}{$\operatorname{lnCEC}$} & $-0.2930^{*}$ & $-0.4392 * * *$ & -0.0297 & $-0.6695 * * *$ \\
\hline & $(0.1697)$ & $(0.1200)$ & $(0.2056)$ & $(0.1882)$ \\
\hline \multirow{2}{*}{$\operatorname{lnFDI}$} & 0.0743 & -0.0366 & 0.0418 & 0.1295 \\
\hline & $(0.1285)$ & $(0.0907)$ & $(0.1558)$ & $(0.1425)$ \\
\hline \multirow{2}{*}{$\operatorname{lnECPG}$} & 0.9955 & 0.5400 & 0.1585 & $2.3069 * *$ \\
\hline & $(0.8562)$ & $(0.6071)$ & (1.0378) & $(0.9503)$ \\
\hline \multirow{2}{*}{$\operatorname{lnER}$} & $-0.1453 * *$ & $-0.1701 * * *$ & $-0.1335 * *$ & $-0.1388 * *$ \\
\hline & $(0.0470)$ & $(0.0332)$ & $(0.0568)$ & $(0.0521)$ \\
\hline \multirow{2}{*}{$\operatorname{lnIS}$} & 0.1317 & 0.0931 & -1.0980 & 1.1487 \\
\hline & $(0.6577)$ & $(0.4637)$ & $(0.7996)$ & $(0.7286)$ \\
\hline \multirow{2}{*}{$\operatorname{lnUR}$} & 1.0116 & $3.2311^{* * *}$ & $2.7362 *$ & 0.8161 \\
\hline & (1.3396) & $(0.9528)$ & $(1.6229)$ & (1.4866) \\
\hline \multicolumn{5}{|c|}{ Wx } \\
\hline \multirow{2}{*}{$\operatorname{lnCEC}$} & 0.4347 & -0.0065 & $0.7991 *$ & 0.3547 \\
\hline & $(0.3954)$ & $(0.2797)$ & $(0.4816)$ & $(0.4389)$ \\
\hline \multirow{2}{*}{$\operatorname{lnFDI}$} & -0.0460 & -0.0534 & -0.2138 & -0.2560 \\
\hline & $(0.2797)$ & $(0.1974)$ & $(0.3371)$ & $(0.3118)$ \\
\hline \multirow{2}{*}{$\operatorname{lnECPG}$} & $-4.0520 * *$ & $-3.8870 * * *$ & $-4.4400 * *$ & $-4.8761 * *$ \\
\hline & $(1.5026)$ & (1.0461) & $(1.8571)$ & (1.6385) \\
\hline \multirow{2}{*}{$\operatorname{lnER}$} & -0.1323 & $-0.1741 * *$ & -0.1739 & -0.0789 \\
\hline & $(0.0975)$ & $(0.0717)$ & $(0.1171)$ & $(0.1091)$ \\
\hline \multirow{2}{*}{$\operatorname{lnIS}$} & 1.7857 & 1.4246 & 2.7921 & 1.0627 \\
\hline & $(1.5429)$ & (1.0876) & $(1.8706)$ & $(1.7126)$ \\
\hline \multirow{2}{*}{$\ln U R$} & 2.1354 & $5.4517 * *$ & 0.7098 & 2.2488 \\
\hline & $(2.5302)$ & (1.8123) & $(3.0674)$ & $(2.7876)$ \\
\hline R-sq & 0.039 & 0.047 & 0.010 & 0.053 \\
\hline LR_lag & $11.5^{*}$ & $21.44 * * *$ & $13.53 * *$ & $13.32 * *$ \\
\hline LR_error & $11.7^{*}$ & $21.62 * * *$ & $13.47 * *$ & $12.10^{* *}$ \\
\hline Wald_lag & $11.85^{* *}$ & $22.77 * * *$ & $14.09 * *$ & $13.80 * *$ \\
\hline Wald_error & $11.5^{*}$ & $22.22 * * *$ & $13.42 * *$ & $11.74 *$ \\
\hline
\end{tabular}

Notes: $\mathrm{z}$-statistics in parenthesis. ${ }^{*}, * *$, and $* * *$ indicate that $\mathrm{p}$ values are less than $0.1,0.05$, and 0.01 levels, respectively.

This further proves that clean energy consumption plays an important role in promoting the decoupling between local economic growth and $\mathrm{SO}_{2}$ emissions and DS emissions. This further validates Hypothesis 1 and 4. However, the average decoupling effect of clean energy consumption on surrounding areas and all regions is not significant.

In addition, we further analyzed the estimated coefficients and significant levels of foreign direct investment, energy consumption per unit of GDP, environmental regulations, industrial structure, urbanization and its spatial lag. It can be discovered:

(1) The regression coefficients of FDI on eCP, eNOx, and eDS are all positive, while the coefficients of the lag term of FDI are all negative, but they fail the significance test. It shows that the increase in FDI in the local area cannot significantly inhibit the decoupling between economic growth and 
Table 5. Estimate results of direct effects, indirect effects and total effects.

\begin{tabular}{|c|c|c|c|c|}
\hline & $\operatorname{lneCP}$ & $\operatorname{lneSO}_{2}$ & $\operatorname{lneNOx}$ & lneDS \\
\hline \multicolumn{5}{|c|}{ LR_Direct } \\
\hline \multirow{2}{*}{$\operatorname{lnCEC}$} & -0.2894 & $-0.4359 * * *$ & -0.0434 & $-0.6560 * * *$ \\
\hline & $(0.1764)$ & $(0.1254)$ & $(0.2175)$ & $(0.1928)$ \\
\hline \multirow{2}{*}{$\operatorname{lnFDI}$} & 0.0692 & -0.0392 & 0.0416 & 0.1161 \\
\hline & $(0.1248)$ & $(0.0885)$ & $(0.1529)$ & $(0.1379)$ \\
\hline \multirow{2}{*}{$\operatorname{lnECPG}$} & 1.1027 & 0.6815 & 0.3843 & $2.2725 * *$ \\
\hline & $(0.8388)$ & $(0.5953)$ & (1.0409) & $(0.9050)$ \\
\hline \multirow{2}{*}{$\operatorname{lnER}$} & $-0.1456^{* *}$ & $-0.1673 * * *$ & $-0.1305 * *$ & $-0.1421 * *$ \\
\hline & $(0.0457)$ & $(0.0323)$ & $(0.0556)$ & $(0.0512)$ \\
\hline \multirow{2}{*}{$\operatorname{lnIS}$} & 0.1053 & 0.0522 & -1.1976 & $1.1618^{*}$ \\
\hline & $(0.6197)$ & $(0.4343)$ & $(0.7453)$ & $(0.7050)$ \\
\hline \multirow{2}{*}{$\operatorname{lnUR}$} & 1.0268 & $3.1441 * *$ & $2.7554^{*}$ & 0.9162 \\
\hline & (1.3349) & $(0.9562)$ & (1.6391) & (1.4555) \\
\hline \multicolumn{5}{|c|}{ LR_Indirect } \\
\hline \multirow{2}{*}{$\operatorname{lnCEC}$} & 0.4306 & 0.0272 & 0.7388 & 0.2983 \\
\hline & $(0.4005)$ & $(0.2706)$ & $(0.4569)$ & $(0.4968)$ \\
\hline \multirow{2}{*}{$\operatorname{lnFDI}$} & -0.0573 & -0.0533 & -0.2133 & -0.2838 \\
\hline & $(0.2692)$ & $(0.1821)$ & $(0.3063)$ & $(0.3387)$ \\
\hline \multirow{2}{*}{$\operatorname{lnECPG}$} & $-4.0140 * *$ & $-3.6987 * * *$ & $-4.1183 * *$ & $-5.0900 * *$ \\
\hline & (1.4773) & (1.0088) & (1.7269) & (1.7802) \\
\hline \multirow{2}{*}{$\operatorname{lnER}$} & -0.1261 & $-0.1469 * *$ & -0.1448 & -0.1020 \\
\hline & $(0.0987)$ & $(0.0660)$ & $(0.1110)$ & $(0.1224)$ \\
\hline \multirow{2}{*}{$\operatorname{lnIS}$} & 1.6936 & 1.2886 & 2.6076 & 1.2484 \\
\hline & (1.5906) & (1.0527) & $(1.7786)$ & $(2.0214)$ \\
\hline \multirow{2}{*}{$\operatorname{lnUR}$} & 2.1351 & $4.8761 * *$ & 0.4095 & 2.6789 \\
\hline & $(2.5161)$ & (1.7417) & (2.8907) & $(3.0820)$ \\
\hline \multicolumn{5}{|c|}{ LR_Total } \\
\hline \multirow{2}{*}{$\operatorname{lnCEC}$} & 0.1412 & -0.4087 & 0.6953 & -0.3577 \\
\hline & $(0.3991)$ & $(0.2615)$ & $(0.4410)$ & $(0.5150)$ \\
\hline \multirow{2}{*}{$\operatorname{lnFDI}$} & 0.0119 & -0.0925 & -0.1717 & -0.1677 \\
\hline & $(0.2825)$ & $(0.1856)$ & $(0.3121)$ & $(0.3676)$ \\
\hline \multirow{2}{*}{$\operatorname{lnECPG}$} & $-2.9113 * *$ & $-3.0172 * * *$ & $-3.7339 * *$ & $-2.8175^{*}$ \\
\hline & $(1.3113)$ & $(0.8685)$ & (1.4468) & (1.6915) \\
\hline \multirow{2}{*}{$\operatorname{lnER}$} & $-0.2717 * *$ & $-0.3142 * * *$ & $-0.2754 * *$ & $-0.2441 *$ \\
\hline & $(0.1101)$ & $(0.0726)$ & $(0.1212)$ & $(0.1401)$ \\
\hline \multirow{2}{*}{$\ln I S$} & 1.7989 & 1.3408 & 1.4100 & 2.4102 \\
\hline & $(1.8228)$ & (1.1925) & $(2.0015)$ & $(2.3584)$ \\
\hline \multirow{2}{*}{$\operatorname{lnUR}$} & 3.1619 & $8.0201 * * *$ & 3.1648 & 3.5951 \\
\hline & $(2.4305)$ & (1.6577) & $(2.6659)$ & $(3.1357)$ \\
\hline
\end{tabular}

Notes: $\mathrm{z}$-statistics in parenthesis. ${ }^{*}, * *$, and $* * *$ indicate that $\mathrm{p}$ values are less than $0.1,0.05$, and 0.01 levels, respectively. 
environmental pollution, and the increase in FDI in neighboring regions cannot significantly promote the decoupling between economic growth and environmental pollution. The estimated coefficients of the indirect spillover effects and total spillover effects of FDI on $\mathrm{eSO}_{2}$, eNOx, and eDS are all negative, but none of them pass the significance test, which shows that FDI cannot promote economic growth and decoupling of environmental pollution.

(2) The regression estimation coefficients of ECPG to decoupling are all positive, but they fail the significance test. The estimated coefficients of the ECPG lag term are all significantly negative at the $5 \%$ level. This indicates that the increase of ECPG in the local area has no significant effect on inhibiting decoupling. The increase of ECPG in the surrounding areas will significantly promote the decoupling of the local area. The direct effects of ECPG on eCP, $\mathrm{eSO}_{2}$, eNOx, and eDS are positive, but they are not significant except for eDS. The indirect and total effects of ECPG are significantly negative, indicating that the increase of local ECPG can significantly promote the decoupling of neighboring regions and all regions through spatial interaction.

(3) The regression estimation coefficient of the decoupling between economic growth and environmental pollution by environmental regulations is significantly negative. The lag coefficient of environmental regulations is also negative, but it fails the significance test. This shows that environmental regulations will significantly promote decoupling. Both the direct and total effects of environmental regulations are significantly negative, and the indirect effects of environmental regulations are also negative but not significant. These results further verify that the increase in the intensity of environmental regulations can significantly promote decoupling. This is consistent with the conclusions of Wang et al. [35] that severely polluting industries tend to relocate to areas with looser environmental regulations, thus turning these areas into polluted paradise. With the transfer of domestic industries, environmental pollution shifts from east to west, while the added value is the opposite. Stricter energy regulation will significantly reduce energy intensity, and companies will also shift their energy structure from using dirty fossil energy to using cleaner energy [36].

(4) The regression estimation coefficient of industrial structure to decoupling is positive, and the lagging term of industrial structure is also positive, but none of them pass the significance test. This shows that the increase in the proportion of the secondary industry cannot significantly inhibit the decoupling in the local area and neighboring areas. The direct effect, indirect effect, and total effect of the industrial structure are all positive, but not significant, which also shows that the increase in the proportion of the secondary industry will not significantly inhibit the decoupling between economic growth and environmental pollution.
(5) The regression estimation coefficient of urbanization on the decoupling between economic growth and $\mathrm{SO}_{2}$ is significantly positive, and its lag coefficient is also significantly positive. This shows that urbanization will significantly inhibit the decoupling of $\mathrm{SO}_{2}$ emissions from economic growth. However, the decoupling effect of urbanization on comprehensive pollution is not obvious. Therefore, urbanization will not significantly inhibit the decoupling between economic growth and environmental pollution in local and neighboring areas. The direct, indirect, and total effects of urbanization are all positive, but only the decoupling effect on $\mathrm{SO}_{2}$ is more significant. This further proves that urbanization only inhibits the decoupling between certain pollutants and economic growth, but not completely. This is consistent with the research conclusions of Liu et al. (2020) [37]. Although extensive urbanization in some areas of China has increased the economic growth rate, it has also caused some environmental pollution.

\section{Conclusion}

The academic contribution of this paper is to interpret the decoupling between economic growth and air pollution from the perspective of spatial econometrics. The results of the decoupling model show that the decoupling of economic growth and environmental pollution is obviously cyclical in time and heterogeneous in space. As time evolves, the relationship between economic growth and environmental pollution of all research objects is increasingly inclined to strong decoupling rather than coupling. The "decoupling" between China's economic growth and environmental pollution has replaced "coupling." However, "weak decoupling" or even "recessive coupling" has appeared in some areas. In the foreseeable future, the decoupling trend of eastern and southern provinces and the coupling trend of northwestern provinces will become more and more obvious.

It can be concluded that clean energy consumption can promote the decoupling between economic growth and environmental pollution, especially in the local area, but the impact of decoupling is not obvious in neighboring areas. Among them, clean energy consumption has the most obvious effect on the decoupling between $\mathrm{SO}_{2}$, DS emissions and economic growth, and the direct effect is a significant negative effect.

\section{Implications}

China should continue to increase the consumption of clean energy. At this stage, to achieve green and sustainable development, the government should formulate energy policies to vigorously develop solar power, wind power, and hydropower. In addition, it is also necessary to formulate supporting energy policies 
such as green certificate trading system and carbon trading system to encourage the consumption of clean energy.

Environmental collaboration between regions should be strengthened. Areas with weak green development foundations such as Gansu, Inner Mongolia, Liaoning, Jilin, and Heilongjiang need industrial assistance and support from decoupled areas with leading green development levels. Thus, breaking the phenomenon of clustering coupling between economic growth and environmental pollution.

Implement a package of supporting policies. It is necessary to strengthen the screening of foreignfunded enterprises, encourage foreign direct investment into the fields of environmental protection and clean energy industries. Strengthen environmental regulations and optimize environmental regulations. In addition, proportion of pollution-intensive industries should be reasonably controlled.

\section{Acknowledgements}

The authors thank the funding from the "Humanities and social sciences research planning fund of the Ministry of education of China" (project approval number: 19XJC630009), "philosophy and social sciences fund of Guangxi Zhuang Autonomous Region" (project approval number: 20AGL001) and the Committee of Guangxi Zhuang Autonomous Region of the Communist Youth League (project approval number: GXGQT2020007).

\section{Conflicts of Interest}

The funders had no role in the design of the study; in the collection, analyses, or interpretation of data; in the writing of the manuscript; or in the decision to publish the results.

\section{References}

1. MYLLYVIRTA., ANALYST. Quantifying the economic costs of air pollution from fossil fuels. Centre for Research on Energy and Clean Air; Paris, France; 2020.

2. GUO X., ZHAO L., CHEN D., JIA Y., CHEN D., ZHOU Y., CHENG S. Prediction of reduction potential of pollutant emissions under the coal cap policy in bth region, China. J Environ Manage, 225, 25, 2018.

3. The State Council of the People's Republic of China, air pollution prevention and control action plan. 2013.

4. Revolutionary Strategy for Energy Production and Consumption (2016-2030). Available online: http://www. gov.cn/xinwen/2017-04/25/5230568/files/286514af354e415 78c57ca38d5c4935b.pdf.( accessed on 28/09/2020)

5. SHEN J. A simultaneous estimation of environmental kuznets curve: evidence from China. China Economic Review, 17 (4), 383, 2006.
6. YANG H., JIA J., ZHOU Y., WANG S. Impact on EKC by trade and FDI in China. China population- Resources and Environment, 15 (3), 99, 2005.

7. RUEFING $\mathrm{K}$. Indicators to measure decoupling of environmental pressure from economic growth (R). Paris: OECD, 2007.

8. TAPIO P. Towards a theory of decoupling: degrees of decoupling in the eu and the case of road traffic in finland between 1970 and 2001. Transport Policy, 12 (2), 137, 2005.

9. WANG Y.H., XIE T.Y., YANG S.L. Carbon emission and its decoupling research of transportation in jiangsu province. Journal of Cleaner Production, 142, 907, 2017.

10. WU X.W., WANG L., ZHENG H.L. A network effect on the decoupling of industrial waste gas emissions and industrial added value: a case study of China. Journal of Cleaner Production, 234, 1338, 2019.

11. QI Y.W. Environmental analysis of carbon emission decoupling and decomposition in regional economic growth in China. Ekoloji, 27 (106), 1443, 2018.

12. XIA H.H., DING L., YANG S.W., WU A.P. Socioeconomic factors of industrial air pollutants in zhejiang province, China: decoupling and decomposition analysis. Environmental Science and Pollution Research. 27 (22), 28247, 2020.

13. LIU B.Q., SU X.L., SHI J.X., HOU R. Does urbanization drive economic growth decoupled from energy consumption in China's logistics? Journal of Cleaner Production, 257, 2020.

14. WANG Q., SU M. The effects of urbanization and industrialization on decoupling economic growth from carbon emission - a case study of China. Sustainable Cities and Society, 51, 2019.

15. DONG F., LI J.Y., WANG Y., ZHANG X.Y., ZHANG S.N., ZHANG S.Q. Drivers of the decoupling indicator between the economic growth and energy-related $\mathrm{CO}_{2}$ in China: a revisit from the perspectives of decomposition and spatiotemporal heterogeneity. Science of The Total Environment, 685, 631, 2019.

16. DONG F., LI J.Y., LI K., SUN Z.Y., YU B.L., WANG Y., ZHANG S.N. Causal chain of haze decoupling efforts and its action mechanism: evidence from 30 provinces in China. Journal of Cleaner Production, 245, 2020.

17. ASUMADU-S S., YADAV P. Achieving a cleaner environment via the environmental kuznets curve hypothesis: determinants of electricity access and pollution in India. Clean Technologies and Environmental Policy, 21 (9), 1883, 2019.

18. CHOVANCOVA J., VAVREK R. (De)coupling analysis with focus on energy consumption in eu countries and its spatial evaluation. Polish Journal of Environmental Studies, 29 (3), 2091, 2020.

19. WANG X.L., GAO X.N., SHAO Q.L., WEI Y.W. Factor decomposition and decoupling analysis of air pollutant emissions in China's iron and steel industry. Environmental Science and Pollution Research, 27 (13), 15267, 2020.

20. MADALENO M., MOUTINHO V. Effects decomposition: separation of carbon emissions decoupling and decoupling effort in aggregated eu-15. Environment Development and Sustainability, 20, 181, 2018.

21. YUAN R., RODRIGUES J.F.D., BEHRENS P. Driving forces of household carbon emissions in China: a spatial decomposition analysis. Journal of Cleaner Production, 233, 932, 2019. 
22. XIA Y. Decoupling and catch-up: a study on the green development path of Chinese cities. Financial Research, 43 (09), 122, 2017.

23. ELHORST J.P. Spatial panel data models. In: spatial econometrics. Springerbriefs in regional science. Springer, Heidelberg, German. 2014

24. PACE R.K., LESAGE J.P. A sampling approach to estimate the log determinant used in spatial likelihood problems. Journal of Geographical Systems, 11 (3), 209, 2009.

25. LIU X., LI S. Empirical analysis of energy efficiency in chinese provinces based on the undesired output sbm model. The practice and understanding of mathematics, 45 (02), 35, 2015.

26. LIU H., LIU W. The analysis of effects of clean energy power generation. Energy Procedia, 152, 947, 2018.

27. LI L., HONG X., WANG J. Evaluating the impact of clean energy consumption and factor allocation on China's air pollution: a spatial econometric approach. Energy, 195, 2020.

28. SHEN N., LIAO H., DENG R., WANG Q. Different types of environmental regulations and the heterogeneous influence on the environmental total factor productivity: empirical analysis of China's industry. Journal of Cleaner Production, 211, 171, 2019.

29. ZHU Y., WANG Z., YANG J., ZHU L. Does renewable energy technological innovation control China's air pollution? A spatial analysis. Journal of Cleaner Production, 250, 2020.

30. LIU J., QU J., ZHAO K. Is China's development conforming to the environmental kuznets curve hypothesis and the pollution haven hypothesis? Journal of Cleaner Production, 234, 787, 2019.

31. ZHENG Y., PENG J., XIAO J., SU P., LI S. Industrial structure transformation and provincial heterogeneity characteristics evolution of air pollution: evidence of a threshold effect from China. Atmospheric Pollution Research, 11 (3), 598, 2020.

32. ZHANG X., WU L., ZHANG R., DENG S., ZHANG Y., WU J., LI Y., LIN L., LI L., WANG Y., WANG L. Evaluating the relationships among economic growth, energy consumption, air emissions and air environmental protection investment in China. Renewable and Sustainable Energy Reviews, 18, 259, 2013

33. HAO Y., ZHENG S., ZHAO M., WU H., GUO Y., LI $\mathrm{Y}$. Reexamining the relationships among urbanization, industrial structure, and environmental pollution in China - new evidence using the dynamic threshold panel model. Energy Reports, 6, 28, 2020.

34. SARKODIE S.A., ADAMS S., LEIRVIK T. Foreign direct investment and renewable energy in climate change mitigation: does governance matter? Journal of Cleaner Production, 263, 2020.

35. WANG Z., CHEN S., CUI C., LIU Q., DENG L. Industry relocation or emission relocation? Visualizing and decomposing the dislocation between China's economy and carbon emissions. Journal of Cleaner Production, 208, 1109, 2019.

36. CHEN D., CHEN S., JIN H., LU Y. The impact of energy regulation on energy intensity and energy structure: firmlevel evidence from China. China Economic Review, 59, 2020.

37. LIU X., SUN T., FENG Q. Dynamic spatial spillover effect of urbanization on environmental pollution in China considering the inertia characteristics of environmental pollution. Sustainable Cities and Society, 53, 2020. 